\title{
Interactive Technology for Inclusive Play
}

\section{Kiley Sobel}

Department of Human Centered

Design \& Engineering

University of Washington

ksobel@uw.edu

\begin{abstract}
In this paper, I describe my current work as a PhD student in HCI. My dissertation research is in how to increase opportunities for children with mixed abilities to equally, actively, and meaningfully participate in the same setting with the assistance of interactive technology. Specifically, I am interested in understanding the ability of interactive technology to support children and their adult guardians with inclusive play, or play among children with different abilities and needs. My research adds to the growing
\end{abstract}

Permission to make digital or hard copies of part or all of this work for personal or classroom use is granted without fee provided that copies are not made or distributed for profit or commercial advantage and that copies bear this notice and the full citation on the first page. Copyright for third-party components of this work must be honored. For all other uses, contact the Owner/Author.

Copyright is held by the owner/author(s).

CHI'16 Extended Abstracts, May 07-12, 2016, San Jose, CA, USA ACM 978-1-4503-4082-3/16/05.

http://dx.doi.org/10.1145/2851581.2859024 movement within HCI toward a social model of disability, and I hope to inspire future technology design based on inclusive principles and the empowerment of all children.

\section{Author Keywords}

Child-computer interaction; inclusion; inclusive design; play; assistive technology.

\section{ACM Classification Keywords}

H.5.m. Information interfaces and presentation (e.g., $\mathrm{HCI}$ ): Miscellaneous.

\section{Research Situation}

I am a third-year PhD student in the Department of Human Centered Design \& Engineering (HCDE) at the University of Washington. I identify as a computer scientist, interaction designer, and social scientist because I have had to employ all of these skills to do research in human-centered computing in HCDE. Although I have yet to formally propose my research, I have been working on research related to my dissertation since I began the PhD program two years ago. I have completed a literature review, qualitative formative work, and a mixed-methods laboratory study all related to my research area. I have a basic plan for what I want to complete for the remainder of my 
thesis, namely iterations on the system I designed and long-term home deployment studies with the systems.

After I complete my General Exam (a combination written and oral exam in theory, research methods, society \& systems, and design, all related to my dissertation topic) in early 2016, I will be able to prepare my formal proposal. After I complete this dissertation proposal soon after $\mathrm{CHI}$, I anticipate taking between one and two years to complete my thesis and graduate (i.e., between Spring 2017 and Spring 2018).

Participating in the doctoral consortium will be beneficial for me because it will allow me to gain critical feedback on my proposed work for the remaining one to two years of my program.

\section{Context/Motivation}

Inclusion, often recognized in reference to inclusive education, relates to having individuals with and without disabilities participate in the same setting. In regard to children, inclusive programs operate based on the notion that engaging children with and without disabilities will positively affect both groups [14]. Children with disabilities benefit from inclusive programs because they are not being implicitly told they are wrong, abnormal, or that they do not deserve to have experiences equal to other children. Inclusive environments support all children to develop important social and emotional skills and an appreciation of human diversity [14]. These positive outcomes "ripple through the community of the setting," helping families of children to build inclusive relationships as well [4].

Despite the benefits of inclusion, there are still barriers to its practice. From the perspective of a social model of disability, which stems from the disability rights movement and disability studies, society actually creates and reinforces disability by defining what is considered "normal" and by structuring the environment in ways that are inaccessible and noninclusive to those who do not fit into this conception. Establishing truly inclusive environments requires social change, a shift in our perspectives, attitudes, and behaviors, and a restructuring of our society and environment. The efforts necessary to enable the active, equal, and meaningful participation of all children coupled with pervasive ableist attitudes on macro-, meso-, and micro-levels prevent children from being able to participate in inclusive settings. In my research, I ask broadly: how can we design interactive technology to help enable and overcome barriers to inclusion for children?

In my work, I specifically focus on play because of its importance for children in inclusive environments. For young children, play is a meaningful, active, pleasurable, and intrinsically motivated-experience and medium for learning [4]. It provides significant learning opportunities that are in line with the goals of inclusion. Through play, young children naturally learn how to communicate, cooperate, make and maintain friendships, control impulses, take different perspectives, and develop other social and emotional skills [8]. But most importantly, I believe every child has the right to play. Play among children with and without disabilities is called inclusive play [4]. Thus, my research is in interactive technology for inclusive play.

I have also concentrated on supporting inclusive play between typically developing (or neurotypical) children and children who are neurodiverse. Children who are 
neurodiverse include those with cognitive,

developmental, learning, social, emotional, behavioral, or other similar disabilities [1]. Designing for children with physical disabilities is also vital but requires additional special examination [9].

\section{Related Work}

Within the HCI community, researchers have done important work in designing technology for and with neurodiverse children, especially those with autism spectrum disorders $[2,11]$. Regarding empathy, friendship development, and other aspects of social and emotional skills, researchers have developed and tested technologies that help neurodiverse children learn through group play (e.g., $[5,6,15])$. These approaches have focused on designing specialized technologies to support play among children with a particular diagnosis. In contrast, I am interested in the design space of technologies that support play among children inclusively. In everyday contexts such as inclusive classrooms, playgrounds, and family life, universal tools that can bridge the gap between neurodiverse and neurotypical children will be more optimal for inclusion than specialized tools for specific populations. However, the prior successes of technologies tested within singular groups suggest promise for those designed for an inclusive population.

Moreover, there seems to be less work in designing technology for inclusive play among children with and without disabilities [16]. Holt et al. [9] explored ways to facilitate meaningful play and the development of social and emotional skills for play among children with and without motor impairments. My work is similar in its goals. However, at this point, I am not investigating physical disabilities. Additionally, Brederode et al. [3] designed powerball, a game for children of mixed abilities to cooperatively fight against a common enemy, which stimulated social interactions. Again, my work is similar in its objective to facilitate group play among children with mixed abilities; however, pOwerball was designed for children ages 8 to 14 . My work aims to build from these technical approaches that promote inclusion, but I focus on a younger population and more unstructured play while also considering the wants and needs of the adults who directly impact young children's play experiences.

\section{Problem Statement}

I have been working on addressing the following question in my work: How can interactive technology increase opportunities for young neurotypical and neurodiverse children to engage in play together? I am working toward answering this question in relation to both collocated play and remote play.

In answering this question, I aim to discern what makes designing technology for play among neurotypical and neurodiverse children distinct from designing for play among children of only one type of group. Specifically I ask: (1) how can interactive technology balance play interactions among children with drastically differing needs? (2) How can interactive technology support children's adult guardians in facilitating this inclusive play? And (3) how can interactive technology help build inclusive relationships among children and encourage them to be more empathetic and accepting?

Research Goals, Methods, \& Status

To answer my research questions, I have four main goals. I have already achieved my first two goals. First, I did qualitative work to understand and describe the 
current state of inclusive play, taking into account the experiences of children, teachers, and parents. This involved design ethnography in an inclusive

kindergarten class, design workshops with children, and interviews and surveys of teachers and parents. I then translated this understanding into considerations for designing interactive tech for inclusive play [16]. Second, using these considerations, I developed my own interactive inclusive play tablet application to examine how interactive technology can balance play interactions between children with differing needs. I used this application as the basis for a mixed-methods short-term laboratory study to empirically evaluate the ability of particular interactive design features to facilitate inclusive play [17]. My results showed that technologically enforcing cooperation between children with mixed abilities supported child pairs who needed scaffolding to play together.

My final two goals comprise the remainder of my dissertation. I estimate to be done with this work on or before Spring 2018. These goals are what I hope to get feedback on during the doctoral consortium as well. First, I aim to transform my design to fully support inclusive play. I will iterate on the design such that it is more adaptive and adjustable to children's differing needs; integrate children's adult guardians into the design to support them in facilitating inclusive play; and develop a remote version of the application to promote inclusive play across distances (i.e., similar to $[10,18,19])$. My formative work and lab study will guide this design iteration. I also plan to do more qualitative work to empirically understand adults' current challenges in setting up, monitoring, and following up on play dates and what the challenges are for children and adults during remote play dates. Lastly, I plan to run mixed-methods long-term home deployment studies with my systems to understand how interactive technology can support children and their adult

guardians with inclusive play both locally and remotely.

\section{Expected Contributions}

My dissertation work will offer an empirical contribution and an artifact contribution. My empirical contribution will be understandings of the design space for interactive technologies for collocated and remote inclusive play; and my artifact contribution will be designed, implemented, and empirically evaluated interactive technologies for inclusive play.

Ultimately, my work adds to the growing movement within the HCI community toward a social model of disability and toward using Disability Studies as a guide to design and develop technology (e.g., [7,13]). I hope to inspire future inclusive technology design based on social perspectives informed by inclusive principles, universal design [12], and the empowerment of all children.

\section{Acknowledgments}

This material is based upon work supported by the National Science Foundation Graduate Research Fellowship under Grant No. DGE-1256082. Any opinion, findings, and conclusions or recommendations expressed in this material are those of the authors and do not necessarily reflect the views of the NSF.

\section{References}

1. Thomas Armstrong. 2013. Neurodiversity: Discovering the extraordinary gifts of autism, ADHD, dyslexia, and other brain differences. Da Capo Press. 
2. Laura Benton, Asimina Vasalou, Rilla Khaled, Hilary Johnson, and Daniel Gooch. 2014. Diversity for design: a framework for involving neurodiverse children in the technology design process. In Proceedings of the 32nd annual ACM conference on Human factors in computing systems (CHI '14). ACM, New York, NY, USA, 3747-3756. DOI=http://doi.acm.org/10.1145/2556288.255724 4

3. Bas Brederode, Panos Markopoulos, Mathieu Gielen, Arnold Vermeeren, and Huib de Ridder. 2005. pOwerball: the design of a novel mixedreality game for children with mixed abilities. In Proceedings of the 2005 conference on Interaction design and children (IDC '05). ACM, New York, NY, USA, 32-39.

DOI=http://dx.doi.org/10.1145/1109540.1109545

4. Theresa Casey. 2005. Inclusive play: Practical strategies for working with children aged 3 to 8 . Sage.

DOI=http://dx.doi.org/10.4135/9781446288252

5. William Farr, Nicola Yuill, Eric Harris, and Steve Hinske. 2010. In my own words: configuration of tangibles, object interaction and children with autism. In Proceedings of the 9th International Conference on Interaction Design and Children (IDC '10). ACM, New York, NY, USA, 3038.

DOI=http://dx.doi.org/10.1145/1810543.1810548

6. William Farr, Nicola Yuill, and Hayes Raffle. 2010 Social benefits of a tangible user interface for children with autistic spectrum conditions. Autism. DOI=http://dx.doi.org/10.1177/136236131036328 0

7. Christopher Frauenberger. 2015. Disability and Technology: A Critical Realist Perspective. In Proceedings of the 17th International ACM SIGACCESS Conference on Computers \& Accessibility (ASSETS '15). ACM, New York, NY,
USA, 89-96.

DOI=http://dx.doi.org/10.1145/2700648.2809851

8. Doris Pronin Fromberg and Doris Bergen. 2006. Play from birth to twelve: Contexts, perspectives, and meanings. Taylor \& Francis. DOI=http://dx.doi.org/10.4324/9780203622650

9. Raymond Holt, Anne-Marie Moore, Angharad Beckett. 2014. Together through play: Facilitating meaningful play for disabled \& non-disabled children through participatory design. Inclusive Designing, 245-255. Springer International Publishing. DOI=http://dx.doi.org/10.1007/978-3319-05095-9_22

10. Kori M. Inkpen, K. 2013. Kids \& video: Playing with friends at a distance. In Connecting Families.

Springer London, 95-123. DOI =http://dx.doi.org/10.1007/978-1-4471-4192 1_6

11. Julie A. Kientz, Matthew S. Goodwin, Gillian R. Hayes, Gregory D. Abowd. 2013. Interactive technologies for autism. Synthesis Lectures on Assistive, Rehabilitative, and Health-Preserving Technologies, 2(2), 1-177.

DOI=http://dx.doi.org/10.2200/s00533ed1v01y20 1309arh004

12. Ron Mace, R. 1997. What is universal design. The Center for Universal Design at NC State University.

13. Jennifer Mankoff, Gillian R. Hayes, and Devva Kasnitz. 2010. Disability studies as a source of critical inquiry for the field of assistive technology. In Proceedings of the 12th international ACM SIGACCESS conference on Computers and accessibility (ASSETS '10), 3-10. DOI=http://doi.acm.org/10.1145/1878803.187880

14. Samuel L. Odom and Karen E. Diamond. 1998. Inclusion of young children with special needs in early childhood education: The research base. Early Childhood Research Quarterly, 13(1), 3-25. 
DOI=http://dx.doi.org/10.1016/s08852006(99)80023-4

15. Anne Marie Piper, Eileen O'Brien, Meredith Ringel Morris, and Terry Winograd. 2006. SIDES: a cooperative tabletop computer game for social skills development. In Proceedings of the 2006 20th anniversary conference on Computer supported cooperative work (CSCW '06). ACM, New York, NY, USA, 1-10.

DOI=http://dx.doi.org/10.1145/1180875.1180877

16. Kiley Sobel, Katie O'Leary, and Julie A. Kientz. 2015. Maximizing children's opportunities with inclusive play: considerations for interactive technology design. In Proceedings of the 14th International Conference on Interaction Design and Children (IDC '15). ACM, New York, NY, USA, 3948. $\mathrm{DOI}=10.1145 / 2771839.2771844$

17. Kiley Sobel, Kyle Rector, Susan Evans, and Julie A. Kientz. 2016. Incloodle: Evaluating an interactive application for young children with mixed abilities. In Proceedings of the SIGCHI Conference on
Human Factors in Computing Systems (CHI '16). ACM, New York, NY, USA.

DOI $=$ http://dx.doi. org/10.1145/2858036.2858114

18. Svetlana Yarosh, Kori M. Inkpen, and A.J.

Bernheim Brush. 2010. Video playdate: toward free play across distance. In Proceedings of the SIGCHI Conference on Human Factors in Computing Systems (CHI '10). ACM, New York, NY, USA, 1251-1260.

DOI=http://dx.doi.org/10.1145/1753326.1753514

19. Svetlana Yarosh, Anthony Tang, Sanika Mokashi, and Gregory D. Abowd. 2013. "almost touching": parent-child remote communication using the sharetable system. In Proceedings of the 2013 conference on Computer supported cooperative work (CSCW '13). ACM, New York, NY, USA, 181192.

DOI=http://dx.doi.org/10.1145/2441776.2441798 